rh 19 Revue d'histoire du XIXe siècle

Société d'histoire de la révolution de 1848 et des

révolutions du XIXe siècle

29 | 2004

Varia

Manuel Charpy, Claire Fredj, Lettres du Mexique. Itinéraires du zouave Augustin-Louis Frélaut 1862-1867, Paris, Éditions Nicolas Philippe, 2003, 399 p.

Odile Roynette

CpenEdition

Journals

Édition électronique

URL : http://journals.openedition.org/rh19/713

DOI : $10.4000 /$ rh19.713

ISSN : $1777-5329$

Éditeur

La Société de 1848

Édition imprimée

Date de publication : 1 décembre 2004

Pagination : 186-188

ISSN : 1265-1354

Référence électronique

Odile Roynette, « Manuel Charpy, Claire Fredj, Lettres du Mexique. Itinéraires du zouave Augustin-Louis

Frélaut 1862-1867, Paris, Éditions Nicolas Philippe, 2003, 399 p. », Revue d'histoire du XIXe siècle [En

ligne], 29 | 2004, mis en ligne le 21 juin 2005, consulté le 22 septembre 2020. URL : http://

journals.openedition.org/rh19/713; DOI : https://doi.org/10.4000/rh19.713

Ce document a été généré automatiquement le 22 septembre 2020

Tous droits réservés 


\title{
Manuel Charpy, Claire Fredj, Lettres du Mexique. Itinéraires du zouave Augustin-Louis Frélaut 1862-1867, Paris, Éditions Nicolas Philippe, 2003, 399 p.
}

\author{
Odile Roynette
}

C'est un document important sur une guerre à la fois méconnue et oubliée que nous livrent Manuel Charpy et Claire Fredj avec ces Lettres du Mexique rédigées par le capitaine de zouaves Augustin-Louis Frélaut et envoyées à son frère Fortuné entre juillet 1862 et avril 1867. Issu de la petite bourgeoisie bretonne qui a choisi la carrière des armes dès le Premier Empire, Frélaut s'est engagé dans l'armée en mars 1848 et il a peu à peu gravi les échelons de la hiérarchie, choisissant en mars 1852 d'entrer dans un corps d'élite, les zouaves, afin d'accélérer ses possibilités d'ascension sociale. Il est alors de tous les combats, en Algérie jusqu'en 1859 puis en Italie où il se bat contre l'Autriche aux côtés des États sardes. Il se voit à cette occasion affecté à la mise en terre des soldats tués lors des batailles meurtrières de Magenta et de Solferino. De retour à Alger après la paix de Villafranca signée en juillet 1859, ce soldat expérimenté est capitaine lorsque arrive en juillet 1862 l'ordre de partir pour le Mexique. Il a trente-cinq ans; il est célibataire comme la plupart des officiers de sa génération et s'il quitte l'Algérie - sa deuxième "patrie » - avec regret, il se soumet avec discipline à la perspective de la guerre qui s'annonce, avec enthousiasme même, persuadé que cette expédition sera victorieuse et de courte durée. Son désenchantement n'en sera que plus profond et plus douloureux.

Décidée par Napoléon III sous le prétexte de contraindre le gouvernement du libéral Benito Juarez à s'acquitter des dettes contractées envers la France, l'expédition qui comporte à ses débuts des contingents espagnols et britanniques est en réalité destinée à combler les rêves de grandeur impériale. Il s'agit non seulement de regagner dans 
l'Hexagone les faveurs des conservateurs et de l'Église de France en s'engageant aux côtés des conservateurs mexicains, mais aussi et surtout d'affirmer la présence française sur tous les continents, y compris sur le continent américain où les États-Unis étendent alors nettement leur influence. La perspective de contrôler les grandes voies de navigation mondiale grâce à un canal qui donnerait un accès aisé à l'Extrême-Orient et à l'Océanie sous-tend aussi le projet de Napoléon III influencé par les saintsimoniens, en particulier par Michel Chevalier, et encouragé par l'exemple du canal de Suez dont les travaux ont commencé après la campagne de Crimée.

Ces considérations politiques et stratégiques échappent toutefois au capitaine Frélaut plongé brutalement avec ses hommes dans un pays inconnu et hostile. Le dépaysement est en effet brutal : les paysages, la faune, la flore, la nourriture et la violence du climat mêlant chaleur extrême et humidité constante, en particulier pendant la saison des pluies, si difficile à supporter sur les " terres chaudes ", mettent à rude épreuve la santé physique et morale des Français décimés par la fièvre jaune, le paludisme et la syphilis, éprouvés par un dépaysement qui se transforme rapidement en une lancinante nostalgie. Les lettres de Frélaut ne cessent en effet de dire la douleur de l'éloignement et le désir, qui devient vite obsessionnel, de rentrer au pays, de retrouver l'affection des siens - frère, mère, cousins et cousines - laissés derrière soi. Ces considérations intimes se mêlent à la description de la guerre menée par Frélaut. Il s'agit pour l'essentiel de coups de main et d'escarmouches menés contre les guérilleros qui infestent le pays et s'en prennent à la population locale pour piller et détruire les villages. Cette contre-guérilla, cette "petite guerre » pour reprendre le langage des soldats, répugne à Frélaut et à ses hommes qui assurent là une mission ingrate, qui peut être comparée, toutes proportions gardées, à celle assumée par l'armée dans l'Hexagone avec le maintien de l'ordre. Elle suscite en tout cas la même répugnance et Frélaut la qualifie souvent «d'absurde métier ». L'occultation de la violence de guerre subie ou exercée par les soldats l'emporte nettement dans les lettres qui nous sont livrées ici. Ce n'est pas une surprise et Frélaut se conforme en cela aux modèles de son temps qui mêlent retenue et pudeur. Toutefois la satisfaction de la mission accomplie et l'absence d'états d'âme sont dites parfois sans détour comme dans cette lettre du 23 novembre 1864 où Frélaut se félicite de sa victoire à Jiquilpan sur les libéraux : « Il nous a fallu donner un de ces coups de collier comme on en donne dans les grands jours et les grandes affaires. Il y a eu une mêlée affreuse, on se tuait à bout portant. J'ai eu le bonheur dans cette circonstance de pouvoir rallier ma compagnie et de faire une trouée dans les masses qui nous entouraient en poussant des cris affreux. Ça a été l'affaire de quelques minutes; nous avons ensuite marché sur leurs cadavres ». Ce professionnel de la violence dit ici sa satisfaction d'avoir tué et, même si cet aveu est rare, il n'en est pas moins révélateur du degré d'intériorisation de la violence qui habite les soldats en campagne.

4 À la pacification proprement dite viennent s'ajouter des missions d'exploration et de contrôle des voies de communication - le travail des officiers d'état-major et des officiers du génie pour établir une cartographie du pays et développer les routes et les voies de chemin de fer est à cet égard essentiel - ainsi qu'un travail d'administrateur. Le pouvoir laissé aux officiers français qui se transforment en juges est considérable et Frélaut à cette occasion se montre convaincu de la mission civilisatrice revendiquée par la France sur les peules extra-européens considérés avec un mépris non dissimulé, partie prenante de la violence du projet colonial. Au fil des jours toutefois, c'est l'absurdité du projet impérial que souligne un peu plus le pouvoir fantoche donné par 
la France en 1864 à l'empereur du Mexique, Maximilien de Habsbourg, la confusion qui règne à la tête de l'armée française, source sur le terrain d'ordres contradictoires, ainsi que l'indignité des notables locaux, grands propriétaires terriens brutaux et clergé mexicain corrompu, qui sont dénoncés avec clairvoyance par Frélaut. Ce dernier fait alors preuve à la fois d'esprit critique et de lucidité sans se départir de la réserve alors exigée de tout officier.

Enfin, au terme de ces lettres c'est à la fois le soulagement à l'annonce du retrait du corps expéditionnaire mais aussi la honte d'abandonner les populations qui avaient soutenu les Français ainsi que le sentiment du gâchis, qui s'expriment intensément chez ce serviteur discipliné, ardent patriote dont la guerre est devenue au fil des années le métier. Elle ne le quitte d'ailleurs pas puisqu'il participe en 1870 au conflit franco-prussien. Blessé à Beaumont, près de Sedan et fait prisonnier le 30 août 1870, il s'évade, poursuit la guerre avec les Républicains et achève sa carrière militaire comme général sous le $\mathrm{III}^{\mathrm{e}}$ République en 1889. C'est le destin d'un homme solitaire, profondément marqué par son métier de soldat que ces lettres nous donnent à voir. Une introduction, une postface intitulée «Lectures» et des notes infrapaginales permettent de les éclairer et de les replacer dans leur contexte. 